\title{
Laboratório de Ensino de Matemática a Distância*
}

\author{
Elton Luiz Vergara Nunes \\ João Artur de Souza ${ }^{* * *}$ \\ Gertrudes Aparecida Dandolini ${ }^{* * *}$
}

Resumo: Este artigo visa a apresentar os princípios que nortearam a criação do Laboratório de Ensino de Matemática a Distância, assim como, a descrever algumas das ferramentas que serão utilizadas. O Laboratório de Ensino de Matemática a Distância foi criado com o objetivo de atender as necessidades do Curso de Matemática nesta nova modalidade de ensino. Este laboratório é essencialmente multidisciplinar e tem como meta principal gerenciar todo o processo que envolve os materiais didáticos da nova Licenciatura.

Palavras-Chave: Ensino a Distância, Matemática, Laboratório Multidisciplinar.

Abstract: This article seeks to present the principles that orientated the creation of the Teaching E-learning Laboratory of Mathematics, as well as, to describe some of the tools that will be used. The Teaching E-learning Laboratory of Mathematics was created with the objective of assisting the needs of the Mathematics Course in this new modality of learning. This laboratory is essentially multidisciplinary and it has as its main goal to manage the whole process that involves the didactic materials of the Degree Course in Mathematics by e-learning.

Keywords: E-learning, Mathematics, multidisciplinary Laboratory.

\section{Apresentação}

O Laboratório de Ensino de Matemática a Distância foi criado com o objetivo de atender as necessidades do Curso de Matemática nesta nova modalidade de ensino. Esse laboratório é peça fundamental para que os objetivos do projeto do Curso sejam alcançados. Não se trata de mera oficina de produção de materiais didáticos, ou núcleo informático de cunho educacional. Trata-se de um espaço de discussão e pesquisa em educação que visa à melhoria da qualidade não somente do curso que é oferecido aos alunos, mas do trabalho docente dos professores e tutores envolvidos no Projeto.

Um laboratório de ensino a distância é essencialmente multidisciplinar rompendo barreiras até pouco tempo intransponíveis. O rompimento de pré-conceitos que encerravam campos do saber em gaiolas transforma-se em desafios. Revela-se tal

\footnotetext{
*Projeto financiado pelo SEED/MEC e FINEP.

** Professor, Mestre em Educação (FAE/UFPEL), Professor de Letras/Espanhol da UFPEL, vergaranunes@gmail.com

*** Professor, Licenciado em Matemática (UFSC) e Doutor em Engenharia de Produção na área de Inteligência Artificial (PPGEP/UFSC), Professor de Matemática e Coordenador do Curso de Matemática a Distância da UFPEL, jgartur@brturbo.com.br

**** Professora, Licenciada em Matemática (UFSC) e Doutora em Engenharia de Produção na área de Inteligência Artificial (PPGEP/UFSC), Professora de Matemática e Coordenadora do Curso de Matemática da UFPEL, ggtude@gmail.com 
propósito com a adoção de uma sólida base teórica no campo do ensino a distância com o conhecimento da matéria a ser ensinada e da metodologia a ser utilizada. Nem só conteúdo nem só o meio, mas uma produção conjunta entre professores, técnicos, estudiosos das tecnologias e da pedagogia dos ambientes virtuais. Basicamente a equipe está composta por técnicos em programação informática e designers, que trabalham com orientação pedagógica do coordenador do Laboratório, além dos professores responsáveis pelas disciplinas. Dentro do Projeto ainda estão previstas a colaboração do trabalho de profissionais ligados à área de comunicação, letras, psicologia, sociologia e todas aquelas que se fizerem necessárias para a melhoria da qualidade do curso.

Cada professor responsável por disciplina é também o responsável pelo planejamento e coordenação na confecção do material didático necessário para seu trabalho. Cabe à equipe do LEMAD assessorar e incrementar o trabalho junto com o professor. Para tanto, a coordenação do Laboratório definirá junto aos membros docentes que comporão o Curso, as linhas de trabalho e os princípios didáticos que devem nortear materiais para ambientes virtuais e outros com base no uso das TICs.

\section{Justificativa}

O ensino a distância é uma realidade imposta não somente pelo mercado, mas pela própria educação, bem identificada já na LDB desde 1996. Desde então, os investimentos tanto do governo como de empresas privadas foram crescendo e os custos dos serviços e equipamentos foram diminuindo. Atualmente, já não se deve limitar a avaliação da viabilidade de investimento a aspectos de curto prazo, nem mesmo cair na tentação de reduzir a educação a mero produto de venda ${ }^{2}$. $\mathrm{O}$ ensino a distância não somente quebra fronteiras e aproxima os que estavam separados, como cria uma nova mentalidade de trabalho colaborativo e de equipes multidisciplinares. Neste ponto de vista devem ser avaliados todos os investimentos feitos na educação. Sem dúvida, o desenvolvimento de competências que ficaram adormecidas no meio universitário em muitos lugares encontram um lugar propício para seu desenvolvimento em ambientes virtuais de ensino. Essas expectativas se direcionam para o desenvolvimento da curiosidade científica, o espírito de colaboração entre os membros envolvidos nos processos, a prática da investigação e o exercício da autonomia. Tudo isto leva à maturidade acadêmica, e, acima de tudo, à mudança nos papéis da escola, que perde seu status de senhora da verdade, do professor, que deixa de ocupar o centro do processo educativo, e do aluno, que não é mais um ser passivo absorvedor de conteúdos estranhos. A construção do conhecimento passa a ser a nova prática da ciência e o processo passa a fazer parte da aprendizagem, cujo resultado final não é um momento mágico, mas uma construção gradativa a longo prazo que pode ser sentida a cada momento.

O LEMAD tem por objetivo principal gerenciar todo o processo que envolve os materiais didáticos do Curso de Licenciatura em Matemática a Distância. Ali se estudam as bases teóricas da comunicação tendo como princípio norteador a "Pedagogia da Internet" (Vergara Nunes, 2002). Os técnicos, professores e demais pessoas

\footnotetext{
${ }^{1}$ Nesta época a Internet - ferramenta maior do atual ensino a distância - recém estava chegando ao Brasil.

${ }^{2}$ Deve-se levar em conta que orçamentos para cursos a distância têm levado desvantagens em relação a cursos presenciais, porque estes, em geral, já contam com uma infra-estrutura instalada, enquanto aqueles precisam incorporar nas despesas previstas gastos com equipamentos, contratação de novos funcionários e mesmo ampliação de instalações físicas.
} 
envolvidas com o trabalho devem ser conhecedores e buscar dominar os diferentes serviços disponíveis na Internet a fim de criar os materiais didáticos específicos para o Curso de Licenciatura de Matemática Distância (CLMD). Entretanto, o uso de diferentes tecnologias como o vídeo, áudio, videoconferência e computador são também adotados para que possa ser feita toda a assessoria necessária para a produção e orientação quanto ao uso dos materiais didáticos nas disciplinas do CLMD. Também cabe a essa equipe a avaliação dos diferentes materiais disponíveis para o ensino de matemática a distância e apoiados pela tecnologia.

1 É no Laboratório de Ensino de Matemática a Distância que o Curso de Licenciatura em Matemática a Distância deverá ter suas atividades mais intensas. Neste local, deverão acontecer as discussões que gerarão a oferta das disciplinas, sua metodologia de trabalho e os materiais didáticos que serão adotados para seu melhor funcionamento. Trata-se de um trabalho multidisciplinar e desafiador.

Entretanto, as discussões são apenas os primeiros passos no trabalho do Laboratório, já que nesse ambiente serão elaborados os materiais e disponibilizados em diferentes meios, sejam eles de áudio, vídeo, impressos, páginas web ou outros. Deverão ser testados previamente em sua funcionalidade e eficácia para um bom ensino a distância. Para tanto, o planejamento é essencial. Por isso, as linhas de trabalho devem estar definidas desde o começo de tal forma que sirvam como firme referencial para não haver improvisos e evitar imprevistos. Flexível o bastante para saber adaptar-se às novas realidades durante o processo de aprendizagem.

No LEMAD os professores acompanharão o desempenho de seus alunos e seu crescimento dentro do curso através de sistemas de monitoramento projetados especialmente para as disciplinas. Todas as ações de caráter acadêmico dos alunos deverão ser monitoradas. Aspectos como o tempo de conexão, caminhos dentro das páginas do ambiente de trabalho adotado ${ }^{3}$, documentos copiados, e-mails recebidos e enviados, participações nos canais de bate-papo, fóruns e listas serão registrados, tabulados e tratados pelo sistema com geração automática de relatórios para apoio à avaliação e acompanhamento dos professores. Todos os dados ficarão à disposição dos responsáveis por disciplinas para que possam usá-los segundo sua necessidade ou relevância para as avaliações. Além disso, o monitoramento constante permite aos professores uma interferência junto aos tutores e monitores para que assessorem mais de perto determinados alunos, ou mesmo o professor possa dar-lhe orientações específicas. A intenção desses mecanismos de monitoramento é ter uma visão completa do trabalho realizado em todas suas etapas, não permitindo que a distância geográfica não seja de forma nenhuma sinônimo de ausência ou vazio de responsabilidade.

No Laboratório estarão instalados os equipamentos para tutoria a distância, onde os professores contarão com equipamentos para conversação via áudio, bate-papo com apoio de webcam, e para acesso a todos os dados disponíveis.

\section{Metodologia de trabalho para a elaboração dos materiais}

2 No começo das atividades do Curso, o Laboratório de Ensino de Matemática a Distância oferecerá um minicurso ${ }^{4}$ de treinamento no uso das diferentes ferramentas a serem adotadas, bem como conhecer os ambientes de trabalho para a realização das aulas. Nesse curso, professores, técnicos e alunos terão a oportunidade de discutir

\footnotetext{
${ }^{3}$ Ver detalhes sobre o ambiente adotado mais adiante.

${ }^{4}$ Este curso poderá ser incluído no currículo dos alunos como Atividade Complementar. 
questões básicas da educação, tais como o papel do professor e do aluno numa perspectiva colaborativa, no ensino a distância. Nesta perspectiva, a ênfase será dada à importância de uma prática pedagógica que respeita as diferenças e os ritmos de cada um. Os princípios da autonomia e do espírito investigador deverão ser base para que o trabalho a ser realizado não tenha problemas de continuidade, já que a distância física/geográfica entre professores e alunos deverá ser compensada por uma presença virtual confiável, permanente e eficaz para que se possa desenvolver um curso de graduação de qualidade.

3 Para tanto, as tutorias e acompanhamento aos alunos deverão ter tratamento especial e serão uma constante de preocupação e trabalho da Coordenação Pedagógica do Curso através do Laboratório.

\subsection{As etapas para a produção de materiais serão divididas basicamente em três:}

Planejamento: Consiste na identificação das necessidades, delimitação dos objetivos da disciplina e/ou dos temas a serem abordados, delimitação dos conteúdos, escolha do melhor meio, desenho do produto.

Produção: Abrange a escolha das ferramentas mais adequadas, aplicação dos princípios teóricos (técnicos das ferramentas e pedagógicos), experimentação e eliminação de falhas técnicas e possibilidades de equívocos no conteúdo, espaço de avaliação e revisão.

Difusão: Disponibilização on-line e/ou distribuição aos pólos.

O acompanhamento de sua aplicação e eficácia será feito especialmente pelos professores responsáveis por disciplinas, tutores e monitores.

\section{Algumas ferramentas da web a serem utilizadas}

\section{Software livre}

O CLMD, através do LEMAD, optou pelo uso de softwares livres por algumas razões, entre elas: pelo aspecto financeiro, já que estes softwares são distribuídos gratuitamente, e por questões técnicas, visto que têm código aberto, podendo ser modificados e adaptados às necessidades específicas de nosso trabalho. Entretanto, será inevitável trabalhar com softwares comerciais tais como os pacotes do Office, Adobe ou Macromedia. Embora os equipamentos adquiridos tenham a licença do sistema operacional Windows, também contarão coma instalação do sistema Linux.

\section{Ferramentas de bate-papo}

Os canais de bate-papo e mesmo softwares como MSN ou ICQ são conhecidos e práticos. Ferramentas como essas devem garantir a oportunidade para alunos e professores manterem contatos mais dinâmicos e tirarem dúvidas sobre questões mais complexas que precisam ser discutidas de forma dinâmica. Além da possibilidade que oferece do contato síncrono para discussões, esses recursos se revestem, por outro lado, da informalidade própria das conversas de bar, onde a aproximação humana se faz mais presente. A equipe técnica do LEMAD está trabalhando na criação de um sistema de bate-papo próprio para o curso, que ofereça não somente suporte para a inserção de fórmulas e equações matemáticas editáveis, mas também onde cada professor será por um lado o moderador das conversas e por outro será o administrador da "sala", 
autorizando participações especiais ou fazendo convites externos. Todos os alunos matriculados na disciplina terão automaticamente autorização (e dever) para participar das conversas da sala. O sistema terá suporte para vídeo e voz e será totalmente monitorado, permitindo aos professores posterior análise da participação do aluno e assim utilizar as atividades ali desenvolvidas como apoio nas avaliações.

\section{Correio eletrônico}

Todo o aluno matriculado no CLMD deverá contar com um endereço de e-mail da instituição que será usado para as atividades acadêmicas. Isto permitirá que o ambiente seja confiável no tocante ao envio e recebimento das mensagens. Sabe-se que uma das desconfianças em relação às mensagens via correio eletrônico é a incerteza de que chegará ao destinatário. Por outro lado, mensagens que chegam e não são lidas não cumprem o seu objetivo que é estabelecer a comunicação. Assim, desta forma se pretende diminuir estas dificuldades e dar mais garantias aos interlocutores.

\section{Fóruns e Listas de Discussão}

Tanto os fóruns como as listas de discussão devem ser um grande apoio para o aprofundamento de determinados aspectos de uma matéria bem como para o estudo de novos temas não previstos no conteúdo programático. As listas e os fóruns poderão ser organizados por disciplinas, por áreas de estudo ou mesmo por tópicos do conteúdo. $\mathrm{O}$ sistema de envio de e-mails e os murais de avisos deverão ser de tal forma configurados que possam servir de um canal a mais de comunicação dentro do ambiente do Curso.

\section{Sites}

O CLMD deverá contar com um portal próprio, dentro do qual estarão organizadas e disponibilizadas todas as páginas web e serviços da internet que alunos, professores e administração podem contar, além das áreas públicas para os usuários e visitantes em geral. Dentro do portal, será disponibilizada uma área restrita de caráter mais acadêmico onde estarão organizadas as disciplinas e os conteúdos a serem trabalhados. O ambiente deverá facilitar o acesso dos alunos ao curso de forma organizada e sistemática, além do caráter didático que os conteúdos serão disponibilizados.

Também estão sendo outros sites especiais, entre eles o laboratório virtual de matemática e o "barzinho". O barzinho é um ambiente de caráter recreativo, pretendendo suprir, por analogia, os bares e salas de recreação das universidades, disponíveis aos alunos de cursos presenciais. Nesse site, o aluno poderá ouvir músicas, assistir filmes, ler artigos, poesias, contos, etc, ou, mesmo, participar de conversação com seus pares sem qualquer tipo de monitoramento ou controle. Nessa área, de caráter mais informal, visa-se à socialização do aluno com seus colegas de outros lugares e desses com os professores. Diferente de todos os demais ambientes do portal, o barzinho não terá nenhum monitoramento de navegação. É a área livre e democrática do curso, embora dali os alunos terão acesso a links que os levem às salas de bate papo, emails, fóruns, e mesmo entrada para o ambiente de trabalho das disciplinas. Um segundo site, o laboratório virtual de matemática, oferecerá situações desafiadoras ao aluno. Ali, o aluno poderá se envolver em jogos individuais (contra o sistema computacional) ou com seus colegas do curso. Também nessa área os alunos poderão lançar desafios e exercícios para seus colegas. Também estarão disponíveis nesse laboratório exercícios interativos on-line, onde os alunos terão a oportunidade de aplicar 
os conhecimentos trabalhados em suas disciplinas. Esta área estará mais ligada ao desenvolvimento das disciplinas do curso $^{5}$ e será monitorada a fim de ajudar na avaliação e acompanhamento do desempenho do aluno.

A equipe de designers está definindo a identidade visual própria do curso e dos ambientes que deverão primar pelo bom gosto estético, usabilidade técnica e praticidade didática. A manutenção do portal e dos sites deverá ser um trabalho em conjunto dos professores e dos técnicos do LEMAD. A manutenção das páginas das disciplinas é de responsabilidade dos professores que poderão contar com o apoio do Laboratório.

\section{Biblioteca Virtual de Matemática}

Para subsidiar o CLMD com material de apoio para o ensino de matemática de qualidade e que motive a pesquisa e a autonomia, a Biblioteca Virtual de Matemática usará uma estrutura projetada com esse fim, já testada e aprovada atualmente em uso no servidor da $\mathrm{UFPel}^{6}$ num trabalho conjunto com a Biblioteca Virtual de Letras. Tal trabalho colaborativo significará a economia de recursos financeiros e a valorização de projetos de pesquisa que vêm alcançando resultados positivos. Nessa Biblioteca, os usuários poderão encontrar artigos com conteúdo didático que poderão ser copiados gratuitamente para uso pessoal. A idéia é abrir um espaço para as publicações acadêmicas em um periódico virtual de matemática com ênfase na aplicação.

\section{Ambiente}

O AMADIS $^{7}$ será usado como ambiente virtual, especialmente reconfigurado pela equipe de técnicos da Universidade Federal do Rio Grande do Sul para o CLMD. A opção por esse ambiente se deve a dois fatores importantes: primeiro pelo trabalho de cooperação que vem acontecendo entre as duas instituições e, segundo, pela potencialidade que o ambiente oferece. Em suas configurações, o Amadis permite o gerenciamento das disciplinas que compõem o curso, bastando para tal que o aluno se matricule apenas uma vez (como acontece no ambiente presencial). $\mathrm{O}$ ambiente oferece as ferramentas típicas de sistemas de educação on-line, além de algumas que estão sendo reconfiguradas para as características de uma licenciatura. Novas ferramentas ${ }^{8}$ estão sendo projetadas por uma equipe de técnicos da área de informática que permitirão um monitoramento mais eficaz e acompanhamento do processo de ensino e aprendizagem dos sujeitos envolvidos no Curso.

A equipe do Laboratório de Ensino de Matemática a Distância da UFPel está trabalhando numa proposta de design que deverá ser incorporada ao ambiente, a fim de possibilitar personalização ao tipo de aluno, horário de conexão, experiência com

\footnotetext{
${ }^{5} \mathrm{O}$ recreio é um dos momentos mais marcantes da vida escolar. No ensino superior, os momentos de encontro das festas e das atividades extraclasse são aquelas que marcam a vida do estudante. Muitos cursos a distância têm ignorado este aspecto social, de grande contribuição para o desenvolvimento da aprendizagem do estudante. Esses aspectos de socialização, que tanta importância têm nos cursos presenciais, não podem ficar relegados a um segundo plano ou - como na maioria dos casos - estar ausentes. Devido à sua ênfase conteudística, muitos projetos de cursos a distância têm pecado no descuido com os fatores sócio-pedagógicos que interferem na aprendizagem.

${ }^{6}$ O projeto prevê um trabalho de colaboração entre a atual Biblioteca Virtual de Letras (http://www.ufpel.edu.br/bvl/) e a futura Biblioteca Virtual de Matemática, compartilhando a mesma estrutura do banco de dados, sistema de busca e gerenciamento.

${ }^{7}$ http://amadis.psico.ufrgs.br/

${ }^{8}$ Aqui nos referimos especialmente a um sistema de e-mail e um chat que permita conversas, apoio à vídeo e áudio, além da possibilidade da inserção de fórmulas matemáticas, com total monitoramento por parte do sistema para futuras avaliações.
} 
Internet, etc. O tipo de atividade a ser executada no ambiente será levada em conta para a escolha do melhor design, a fim de criar um ambiente que motive a aprendizagem.

Ao entrar no ambiente, o aluno será identificado ${ }^{9}$ através de um login e uma senha que permitirá personalizar o acesso. Cada professor responsável por disciplina, ao ser logado, terá a sua disposição ferramentas de administração do site que lhe permitirá inserção de conteúdos, habilitação de áreas e ferramentas de trabalho dentro da página própria da disciplina, bem como o monitoramento dos dados relativos aos alunos matriculados na disciplina. Dentro do site estarão os links necessários para ferramentas de comunicação como o webmail, chat, listas, fóruns, agenda, etc.

\section{Conclusão}

O gerenciamento de todo processo que envolve os materiais didáticos de um curso deve estar centralizado num ambiente que possa reunir todos os profissionais para apresentar a coesão tão esperada nesta nova metodologia de trabalho. As bases teóricas devem ser discutidas e aprimoradas por todos os envolvidos na utilização dos mais variados recursos disponíveis. A análise das diferentes tecnologias não pode ser observada do ponto de vista individual e sim coorporativo. O conjunto deve ser bem homogêneo nas discussões e desenvolvimentos, não se pode esperar de um único profissional toda a eficiência na produção.

O planejamento é essencial e define todos os passos no trabalho do Laboratório. Cada etapa é previamente analisada, escalonada e distribuída num processo colaborativo e de grupo, flexível o bastante para adaptar-se às novas realidades. O LEMAD é o centro do curso, onde estão as discussões mais intensas, onde o trabalho multidisciplinar se faz necessário, onde a metodologia de utilização dos materiais didáticos é aplicada. Promovendo, assim, um processo de ensino a distância de qualidade.

\section{Referências Bibliográficas}

GUARANYS, L.R. dos. CASTRO, C.M. O ensino por correspondência: uma estratégia de desenvolvimento educacional no Brasil. Brasília: IPEA, 1979.

MACHADO, E. EAD - Algo mais Amplo que Ensino a Distância. Texto 85, lista de Discussão - "Desafios Educacionais" Coordenação: Conselho de Educação do Ceará Disponível em: < http://www.cec.ce.gov.br > . Acesso em: 28 nov. 1999.

VERGARA NUNES, Elton L. Pedagogia da internet. Pelotas: FAE/UFPel, 2002, Dissertação de Mestrado.

\footnotetext{
${ }^{9}$ Os pesquisadores do LEMAD estão investigando um sistema de identificação que impeça que outras pessoas - que não o próprio aluno ou o professor - de posse de um login e uma senha que não lhe pertençam acessem o ambiente. O sistema de identificação estará baseado em identificação da imagem e da voz do usuário, que será comparada com um padrão gravado no banco de dados. Em caso de identificação positiva, o sistema permite a entrada, em caso de negativa, ou de conexão onde não haja microfone ou webcam, a entrada poderá ser feita por login e senha, porém esse acesso será checado posteriormente para confirmação dos trabalhos executados.
} 